\title{
Some remarks on b-(E.A)-property in b-metric spaces
}

\author{
Vildan Ozturk ${ }^{1 *}$ and Stojan Radenović 2,3
}

\author{
${ }^{*}$ Correspondence: \\ vildan_ozturk@hotmail.com; \\ vildanozturk84@gmail.com \\ ${ }^{1}$ Department of Business \\ Administration, \\ Faculty of Economics \\ and Administrative Science, \\ Artvin Coruh University, \\ 08000 Artvin, Turkey \\ Full list of author information \\ is available at the end of the \\ article
}

\begin{abstract}
In this paper we consider, discuss, improve and generalize recent b-(E.A)-property results for mappings in b-metric spaces established by Ozturk and Turkoglu (J Nonlinear Convex Anal 16(10):2059-2066, 2015). Thus, all our results are with much shorter proofs. One example is given to support the result.
\end{abstract}

Keywords: (E.A)-property, Common fixed point, Weakly compatible, b-Metric space, Well-posedness

Mathematics Subject Classification: 47H10, 54H25

\section{Introduction and preliminaries}

Banach contraction principle (Banach 1922) was proved in 1922. After many generalizations of this principle were introduced in metric spaces. Also, in recent years some important generalizations of usual metric spaces were defined. $b$-metric space (Bakhtin 1989; Czerwik 1993) or metric type spaces-MTS by some authors (Hussain et al. 2012; Jovanović et al. 2010; Khamsi and Hussain 2010; Stanić et al. 2012) is well known generalizations of (usual) metric. Also several interesting results about the existence and uniqueness of fixed point were proved in $b$-metric spaces (Aghajani et al. 2014; AminiHarandi 2014; Bakhtin 1989; Czerwik 1993; Ding et al. 2015a, b; Hussain et al. 2012, 2013; Jovanović et al. 2010; Khamsi and Hussain 2010; Kir and Kiziltunc 2013; Ozturk and Turkoglu 2015; Radenović and Kadelburg 2011; Roshan et al. 2013, 2014).

The following definition is introduced in Bakhtin (1989) and Czerwik (1993).

Definition 1 (Bakhtin 1989; Czerwik 1993) Let $X$ be a (nonempty) set and $s \geq 1$ be a given real number. A function $d: X \times X \rightarrow[0, \infty)$ is a $b$-metric on $X$ if, for all $x, y, z \in X$, the following conditions hold:

(b1) $d(x, y)=0$ if and only if $x=y$,

(b2) $d(x, y)=d(y, x)$,

(b3) $\quad d(x, z) \leq s[d(x, y)+d(y, z)]$ (b-triangular inequality).

In this case, the pair $(X, d)$ is called a $b$-metric space (metric type space).

It should be noted that, the class of $b$-metric spaces is effectively larger than that of metric spaces, every metric is a $b$-metric with $s=1$, while the converse is not true.

(c) 2016 Ozturk and Radenović. This article is distributed under the terms of the Creative Commons Attribution 4.0 International License (http://creativecommons.org/licenses/by/4.0/), which permits unrestricted use, distribution, and reproduction in any medium, provided you give appropriate credit to the original author(s) and the source, provide a link to the Creative Commons license, and indicate if changes were made. 
Example 2 Let $(X, d)$ be a metric space and $\rho(x, y)=(d(x, y))^{p}$, where $p>1$ is a real number. Then $\rho$ is a $b$-metric with $s=2^{p-1}$.

However, if $(X, d)$ is a metric space, then $(X, \rho)$ is not necessarily a metric space.

For example, if $X=\mathbb{R}$ is the set of real numbers and $d(x, y)=|x-y|$ is usual Euclidean metric, then $\rho(x, y)=(x-y)^{2}$ is a $b$-metric on $\mathbb{R}$ with $s=2$. But is not a metric on $\mathbb{R}$.

Definition 3 (Jovanović et al. 2010) Let $\left\{x_{n}\right\}$ be a sequence in a $b$-metric space $(X, d)$.

(a) $\left\{x_{n}\right\}$ is called $b$-convergent if and only if there is $x \in X$ such that $d\left(x_{n}, x\right) \rightarrow 0$ as $n \rightarrow \infty$.

(b) $\left\{x_{n}\right\}$ is a $b$-Cauchy sequence if and only if $d\left(x_{n}, x_{m}\right) \rightarrow 0$ as $n, m \rightarrow \infty$.

A $b$-metric space is said to be complete if and only if each $b$-Cauchy sequence in this space is $b$-convergent.

Proposition 4 (Jovanović et al. 2010) In a b-metric space $(X, d)$, the following assertions hold:

p1. A b-convergent sequence has a unique limit.

p2. Each b-convergent sequence is b-Cauchy.

p3. In general, a b-metric is not continuous.

Definition 5 (Hussain and Shah 2011) Let $(X, d)$ be a $b$-metric space. A subset $Y \subset X$ is called closed if and only if for each sequence $\left\{x_{n}\right\}$ in $Y$ which $b$-converges to an element $x$, we have $x \in Y$.

On the other hand (E.A)-property was introduced by Aamri and Moutawakil (2002). Later some authors introduced some new fixed point results using this concept (Ali et al. 2010; Babu and Sailaja 2011; Nazir and Abbas 2014; Ozturk and Turkoglu 2015). In this paper, we prove a common fixed point theorem for two pairs of mappings which satisfy the $b$-(E.A) property in $b$-metric spaces (Ozturk and Turkoglu 2015).

Definition 6 Let $(X, d)$ be a $b$-metric space and $f$ and $g$ be selfmappings on $X$.

(i) $f$ and $g$ are said to compatible if whenever a sequence $\left\{x_{n}\right\}$ in $X$ is such that $\left\{f x_{n}\right\}$ and $\left\{g x_{n}\right\}$ are $b$-convergent to some $t \in X$, then $\lim _{n \rightarrow \infty} d\left(f g x_{n}, g f x_{n}\right)=0$.

(ii) $f$ and $g$ are said to noncompatible if there exists at least one sequence $\left\{x_{n}\right\}$ in $X$ is such that $\left\{f x_{n}\right\}$ and $\left\{g x_{n}\right\}$ are $b$-convergent to some $t \in X$, but $\lim _{n \rightarrow \infty} d\left(f g x_{n}, g f x_{n}\right)$ is either nonzero or does not exist.

(iii) Ozturk and Turkoglu (2015) $f$ and $g$ are said to satisfy the $b$-(E.A) property if there exists a sequence $\left\{x_{n}\right\}$ such that

$$
\lim _{n \rightarrow \infty} f x_{n}=\lim _{n \rightarrow \infty} g x_{n}=t,
$$

for some $t \in X$. 
Remark 7 Noncompatibility implies $b$-(E.A)-property.

Example 8 Ozturk and Turkoglu (2015) Let $X=[0,2]$ and define $d: X \times X \rightarrow[0, \infty)$ as follows

$$
d(x, y)=(x-y)^{2}
$$

Let $f, g: X \rightarrow X$ be defined by

$$
f(x)=\left\{\begin{array}{ll}
1, & x \in[0,1] \\
\frac{x+1}{8}, & x \in(1,2]
\end{array} \quad g(x)=\left\{\begin{array}{ll}
\frac{3-x}{2}, & x \in[0,1] \\
\frac{x}{4}, & x \in(1,2]
\end{array} .\right.\right.
$$

For a sequence $\left\{x_{n}\right\}$ in $X$ such that $x_{n}=1+\frac{1}{n+2}, n=0,1,2, \ldots$ and

$$
\lim _{n \rightarrow \infty} f x_{n}=\lim _{n \rightarrow \infty} g x_{n}=\frac{1}{4} .
$$

So $f$ and $g$ are satisfy the $b$-(E.A) property. $\lim _{n \rightarrow \infty} d\left(f g x_{n}, g f x_{n}\right)$ exists and it is not equal to 0 . Thus $f$ and $g$ are noncompatible.

Definition 9 (Jungck 1986) $f$ and $g$ be given self-mappings on a set $X$. The pair $(f, g)$ is said to be weakly compatible if $f$ and $g$ commute at their coincidence points (i.e. $f g x=g f x$ whenever $f x=g x)$.

\section{Main results}

In our first result of this section, we generalize, complement and improve recent results from (Ozturk and Turkoglu 2015, Theorems 2.1, Corollaries 2.2; 2.3 and Example 2.4) for b-metric spaces with much shorter proofs. We begin with our first result.

Theorem 10 Let $(X, d)$ be a b-metric space with $s>1$ and $f, g, S, T: X \rightarrow X$ be a mappings with $f(X) \subseteq T(X)$ and $g(X) \subseteq S(X)$ such that

$$
s^{\varepsilon} d(f x, g y) \leq M_{s}(x, y), \quad \text { for all } x, y \in X
$$

where $\varepsilon>1$ is a constant and

$$
M_{s}(x, y)=\max \left\{d(S x, T y), d(f x, S x), d(g y, T y), \frac{d(f x, T y)+d(S x, g y)}{2 s}\right\} .
$$

Suppose that one of the pairs $(f, S)$ and $(g, T)$ satisfy the $b$-(E.A)-property and that one of the subspaces $f(X), g(X), S(X)$ and $T(X)$ is b-closed in $X$. Then the pairs $(f, S)$ and $(g, T)$ have a point of coincidence in X.Moreover, if the pairs $(f, S)$ and $(g, T)$ are weakly compatible, then $f, g$, S and Thave a unique common fixed point.

Proof If the pair $(f, S)$ satisfies the $b$ - $(E . A)$-property, then there exists a sequence $\left\{x_{n}\right\}$ in $X$ satisfying

$$
\lim _{n \rightarrow \infty} f x_{n}=\lim _{n \rightarrow \infty} S x_{n}=q,
$$


for some $q \in X$. As $f(X) \subseteq T(X)$ there exists a sequence $\left\{y_{n}\right\}$ in $X$ such that $f x_{n}=T y_{n}$. Hence $\lim _{n \rightarrow \infty} T y_{n}=q$. Let us show that $\lim _{n \rightarrow \infty} g y_{n}=q$. By (1),

$$
s^{\varepsilon} d\left(f x_{n}, g y_{n}\right) \leq M_{s}\left(x_{n}, y_{n}\right)
$$

where

$$
\begin{aligned}
M_{s}\left(x_{n}, y_{n}\right) & =\max \left\{\begin{array}{c}
d\left(S x_{n}, T y_{n}\right), d\left(f x_{n}, S x_{n}\right), d\left(T y_{n}, g y_{n}\right), \\
\frac{d\left(S x_{n}, g y_{n}\right)+d\left(f x_{n}, T y_{n}\right)}{2 s}
\end{array}\right\} \\
& =\max \left\{\begin{array}{c}
d\left(S x_{n}, f x_{n}\right), d\left(f x_{n}, S x_{n}\right), d\left(f x_{n}, g y_{n}\right), \\
\frac{d\left(S x_{n}, g y_{n}\right)+d\left(f x_{n}, f x_{n}\right)}{2 s}
\end{array}\right\}, \\
& \leq \max \left\{\begin{array}{c}
d\left(S x_{n}, f x_{n}\right), d\left(f x_{n}, g y_{n}\right), \\
\frac{s\left[d\left(S x_{n}, f x_{n}\right)+d\left(f x_{n}, g y_{n}\right)\right]}{2 s}
\end{array}\right\} \\
& =\max \left\{d\left(S x_{n}, f x_{n}\right), d\left(f x_{n}, g y_{n}\right)\right\} .
\end{aligned}
$$

In (2), on taking limit superior, we obtain

$$
\begin{aligned}
\varlimsup_{n \rightarrow \infty} s^{\varepsilon} d\left(f x_{n}, g y_{n}\right) & \leq \varlimsup_{n \rightarrow \infty} \max \left\{d\left(S x_{n}, f x_{n}\right), d\left(f x_{n}, g y_{n}\right)\right\} \\
& \leq \varlimsup_{n \rightarrow \infty} d\left(f x_{n}, g y_{n}\right),
\end{aligned}
$$

because $d\left(S x_{n}, f x_{n}\right) \rightarrow 0$ as $n \rightarrow \infty$. Since $s^{\varepsilon}>s>1$, we get that

$$
\varlimsup_{n \rightarrow \infty} d\left(f x_{n}, g y_{n}\right)=0
$$

that is $\lim _{n \rightarrow \infty} d\left(f x_{n}, g y_{n}\right)=0$. Further, we have

$$
\frac{1}{s} d\left(q, g y_{n}\right) \leq d\left(q, f x_{n}\right)+d\left(f x_{n}, g y_{n}\right) \rightarrow 0,
$$

as $n \rightarrow \infty$, thus $g y_{n} \rightarrow q$ as $n \rightarrow \infty$.

If $T(X)$ is closed subspace of $X$, then there exists a $r \in X$, such that $\operatorname{Tr}=q$. We shall show that $g r=q$. Indeed, we have

$$
\begin{aligned}
\frac{1}{s} d(q, g r) & \leq d\left(q, f x_{n}\right)+d\left(f x_{n}, g r\right) \\
& \leq d\left(q, f x_{n}\right)+\frac{1}{s^{\varepsilon}} M_{s}\left(x_{n}, r\right),
\end{aligned}
$$

where

$$
\begin{aligned}
M_{s}\left(x_{n}, r\right) & =\max \left\{\begin{array}{c}
d\left(S x_{n}, T r\right), d\left(f x_{n}, S x_{n}\right), d(\operatorname{Tr}, g r), \\
\frac{d\left(f x_{n}, T r\right)+d\left(S x_{n}, g r\right)}{2 s}
\end{array}\right\} \\
& =\max \left\{\begin{array}{c}
d\left(S x_{n}, q\right), d\left(f x_{n}, S x_{n}\right), d(q, g r), \\
\frac{d\left(f x_{n}, q\right)+d\left(S x_{n}, g r\right)}{2 s}
\end{array}\right\} \\
& \leq \max \left\{\begin{array}{c}
d\left(S x_{n}, q\right), d\left(f x_{n}, S x_{n}\right), d(q, g r), \\
\frac{d\left(f x_{n}, q\right)+s d\left(S x_{n}, q\right)+s d(q, g r)}{2 s}
\end{array}\right\} .
\end{aligned}
$$


Letting $n \rightarrow \infty$, we have

$$
\lim _{n \rightarrow \infty} M_{s}\left(x_{n}, r\right) \leq \max \left\{0,0, d(q, g r), \frac{d(q, g r)}{2}\right\}=d(q, g r) .
$$

Now, (3) implies

$$
\frac{1}{s} d(q, g r) \leq 0+\frac{1}{s^{\varepsilon}} d(q, g r),
$$

from which it follows $d(q, g r)=0$ (because $\left.s^{\varepsilon}>s\right)$. Hence, $q=g r=\operatorname{Tr}$, that is $r$ is the coincidence point of pair $(g, T)$. As $g(X) \subseteq S(X)$, there exists a point $z \in X$ such that $q=S z$. We claim that $S z=f z$. By (1), we have

$$
s^{\varepsilon} d(f z, g r) \leq M_{s}(z, r)
$$

where

$$
\begin{aligned}
M_{s}(z, r) & =\max \left\{d(S z, T r), d(f z, S z), d(\operatorname{Tr}, g r), \frac{d(f z, T r)+d(S z, g r)}{2 s}\right\} \\
& =\max \left\{0, d(f z, q), 0, \frac{d(f z, q)+0}{2 s}\right\} \\
& =d(f z, q) .
\end{aligned}
$$

Thus from (4),

$$
s^{\varepsilon} d(f z, g r) \leq d(f z, q)=d(f z, g r),
$$

from which it follows that $d(f z, g r)=0$. Therefore $S z=f z=q$. Hence $z$ is the coincidence point of the pair $(f, S)$. Thus $f z=S z=g r=T r=q$. By the weak compatibility of the pairs $(f, S)$ and $(g, T)$, we btain that $f q=S q$ and $g q=T q$.

We will show that $q$ is a common fixed point of $f, g, S$ and $T$. From (1) we have

$$
s^{\varepsilon} d(f q, q)=s^{\varepsilon} d(f q, g r) \leq M_{s}(q, r)
$$

where,

$$
\begin{aligned}
M_{s}(q, r) & =\max \left\{d(S q, T r), d(f q, S q), d(\operatorname{Tr}, g r), \frac{d(f q, T r)+d(S q, g r)}{2 s}\right\} \\
& =\max \left\{d(f q, q), d(f q, f q), d(q, q), \frac{d(f q, q)+d(f q, q)}{2 s}\right\} \\
& =d(f q, q) .
\end{aligned}
$$

By (5)

$$
s^{\varepsilon} d(f q, q) \leq d(f q, q)
$$

from which it follows $f q=S q=q$. Similarly, it can be shown $g q=T q=q$.

To prove the uniqueness of fixed point, suppose that $p$ is another fixed point of $f, g, S$ ad $T$. By (1), 


$$
s^{\varepsilon} d(q, p)=s^{\varepsilon} d(f q, g p) \leq M_{s}(q, p)
$$

where

$$
\begin{aligned}
M_{s}(q, p) & =\max \left\{d(S q, T p), d(f q, S q), d(T p, g p), \frac{d(f q, T p)+d(S q, g p)}{2 s}\right\} \\
& =\max \left\{d(q, p), d(q, q), d(p, p), \frac{d(q, p)+d(q, p)}{2 s}\right\} \\
& =d(q, p) .
\end{aligned}
$$

Hence, we have

$$
s^{\varepsilon} d(q, p) \leq d(q, p),
$$

from which again follows that $d(q, p)=0$. So $q=p$.

Remark 11 Since the condition (1) from Ozturk and Turkoglu (2015) implies (1) for all altering functions $\psi$ and $\varphi$ (Khan et al. 1984; Radenović et al. 2012) and for each $\varepsilon \in(1,2]$ we get that our Theorem 9 is genuine generalization of the main result from Ozturk and Turkoglu (2015). However, the main result from Ozturk and Turkoglu (2015) holds if $s=1$, what is not case for our Theorem 9. Also, the main result from Ozturk and Turkoglu (2015) holds if $s>1$ and $\varepsilon \in(1, \infty)$ for given altering functions $\psi$ and $\varphi$.

Corollary 12 Let $(X, d)$ be a b-metric space and $f, T: X \rightarrow X$ be mappings such that

$$
\left.s^{\varepsilon} d(f x, f y)\right) \leq M_{s}(x, y) \quad \text { for all } x, y \in X,
$$

where $\varepsilon>1$ is a constant and

$$
M_{s}(x, y)=\max \left\{d(T x, T y), d(f x, T x), d(f y, T y), \frac{d(f x, T y)+d(T x, f y)}{2 s}\right\},
$$

Suppose that the pair $(f, T)$ satisfies the b-(E.A)-property and $T(X)$ is closed in $X$. Then the pair $(f, T)$ has a unique point of coincidence in X. Moreover, if the pair $(f, T)$ is weakly compatible, then $f$ and $T$ have a unique common fixed point.

Corollary 13 Let $(X, d)$ be a b-metric space and $f, T: X \rightarrow X$ be mappings such that

$$
\left.s^{2} d(f x, f y)\right) \leq M_{s}(x, y) \quad \text { for all } x, y \in X,
$$

where $\varepsilon>1$ is a constant and

$$
M_{s}(x, y)=\max \left\{d(T x, T y), d(f x, T x), d(f y, T y), \frac{d(f x, T y)+d(T x, f y)}{2 s}\right\},
$$

Suppose that the pair $(f, T)$ satisfies the $b$ - $(E . A)$-property and $T(X)$ is closed in $X$. Then the pair $(f, T)$ has a unique point of coincidence in X. Moreover, if the pair $(f, T)$ is weakly compatible, then $f$ and $T$ have a unique common fixed point. 
Example 14 Let $X=[0,1]$ and define $d: X \times X \rightarrow[0, \infty)$ as follows

$$
d(x, y)=\left\{\begin{array}{ll}
0, & x=y \\
(x+y)^{2}, & x \neq y
\end{array} .\right.
$$

Then $(X, d)$ is a $b$-metric space with $s=2$. Let $f, g, S, T: X \rightarrow X$ be defined by

$$
f(x)=\frac{x}{4} \quad S(x)=\left\{\begin{array}{l}
2 x, 0 \leq x<\frac{1}{2} \\
1, \quad x=\frac{1}{2} \\
\frac{1}{8}, \quad \frac{1}{2}<x \leq 1
\end{array}, \quad g(x)=0 \quad \text { and } T(x)=x .\right.
$$

Clearly, $g(X)$ is closed, $f(X) \subseteq T(X)$ and $g(X) \subseteq S(X)$. The sequence $\left\{x_{n}\right\}, x_{n}=\frac{1}{2}+\frac{1}{n}$, is in $X$ such that $\lim _{n \rightarrow \infty} f x_{n}=\lim _{n \rightarrow \infty} S x_{n}=\frac{1}{8}$. So that the pair $(f, S)$ satisfies the $b$-(E.A)-property. But the pair $(f, S)$ is noncompatible because $\lim _{n \rightarrow \infty} d\left(f S x_{n}, S f x_{n}\right) \neq 0$. To check the contractive condition (1), for all $x, y \in X$, and $\varepsilon=2$,

if $x=0$, then (1) is satisfied.

If $x \in\left(0, \frac{1}{2}\right)$, then

$$
\begin{aligned}
& s^{\varepsilon} d(f x, g y)=2^{2} \cdot\left(\frac{x}{4}\right)^{2} \leq\left(\frac{9 x}{4}\right)^{2}=d(f x, S x) \leq M_{s}(x, y) . \\
& \text { If } x=\frac{1}{2} \text {, then } \\
& s^{\varepsilon} d(f x, g y)=2^{2} \cdot\left(\frac{1}{8}\right)^{2} \leq\left(\frac{1}{8}+1\right)^{2}=d(f x, S x) \leq M_{s}(x, y) .
\end{aligned}
$$

If $x \in\left(\frac{1}{2}, 1\right]$, then

$$
s^{\varepsilon} d(f x, g y)=2^{2} \cdot\left(\frac{x}{4}\right)^{2} \leq\left(\frac{x}{4}+\frac{1}{8}\right)^{2}=d(f x, S x) \leq M_{s}(x, y) .
$$

Thus (1) is satisfied for all $x, y \in X$. The pairs $(f ; S)$ and $(g ; T)$ are weakly compatible. Hence, all the conditions of Theorem 9 are satisfied. Moreover 0 is the unique common fixed point of $f ; g ; S$ and $T$.

The following results are similar to previously and the proofs are omitted.

Theorem 15 Let $(X, d)$ be a b-metric space with $s>1$ and $f, g, S, T: X \rightarrow X$ be a mappings with $f(X) \subseteq T(X)$ and $g(X) \subseteq S(X)$ such that

$$
s^{\varepsilon} d(f x, g y) \leq M_{s}(x, y), \quad \text { for all } x, y \in X
$$

where $\varepsilon>1$ is a constant and

$$
M_{s}(x, y)=\max \left\{d(S x, T y), \frac{d(f x, S x)+d(g y, T y)}{2 s}, \frac{d(f x, T y)+d(S x, g y)}{2 s}\right\} .
$$


Suppose that one of the pairs $(f, S)$ and $(g, T)$ satisfy the $b$-(E.A)-property and that one of the subspaces $f(X), g(X), S(X)$ and $T(X)$ is b-closed in $X$. Then the pairs $(f, S)$ and $(g, T)$ have a point of coincidence in $X$. Moreover, if the pairs $(f, S)$ and $(g, T)$ are weakly compatible, then $f, g$, S and T have a unique common fixed point.

Theorem 16 Let $(X, d)$ be a b-metric space with $s>1$ and $f, g, S, T: X \rightarrow X$ be a mappings with $f(X) \subseteq T(X)$ and $g(X) \subseteq S(X)$ such that

$$
s^{\varepsilon} d(f x, g y) \leq M_{s}(x, y), \quad \text { for all } x, y \in X
$$

where $\varepsilon>1$ is a constant and

$$
M_{s}(x, y)=\max \{d(S x, T y), d(f x, S x), d(g y, T y), d(f x, T y), d(S x, g y)\} .
$$

Suppose that one of the pairs $(f, S)$ and $(g, T)$ satisfy the $b$-(E.A)-property and that one of the subspaces $f(X), g(X), S(X)$ and $T(X)$ is b-closed in $X$. Then the pairs $(f, S)$ and $(g, T)$ have a point of coincidence in $X$. Moreover, if the pairs $(f, S)$ and $(g, T)$ are weakly compatible, then $f, g$, S and Thave a unique common fixed point.

\section{Well posedness result}

Definition 17 (Boriceanu et al. 2010) Let $(X, d)$ be a $b$-metric space and $f: X \rightarrow X$ be a mapping. The fixed point problem of $f$ said to be well-posed iff

(i) $f$ has a unique fixed point $q$ in $X$,

(ii) If $x_{n} \in X, n \in \mathbb{N}$ and $d\left(x_{n}, T x_{n}\right) \rightarrow 0$ as $n \rightarrow \infty$, then $d\left(x_{n}, q\right) \rightarrow 0$ as $n \rightarrow \infty$.

Theorem 18 Let $(X, d)$ be a b-metric space with $s>1$ and $f, g, S, T: X \rightarrow X$ be a mappings. Suppose that all hypotheses of Theorem 9 hold. Then the fixed point problem is well posed for mappings $f, g, S$ and $T$.

Proof By Theorem 9, The mappings $f, g, S$ and $T$ have a unique common fixed point (say) $q$ in $X$.Let $\left\{x_{n}\right\}$ be a sequence in $X$ such that

$$
\begin{aligned}
\lim _{n \rightarrow \infty} d\left(f x_{n}, x_{n}\right) & =\lim _{n \rightarrow \infty} d\left(g x_{n}, x_{n}\right)=\lim _{n \rightarrow \infty} d\left(T x_{n}, x_{n}\right) \\
& =\lim _{n \rightarrow \infty} d\left(S x_{n}, x_{n}\right)=0 .
\end{aligned}
$$

Using (1) and triangular inequality, we have

$$
\begin{aligned}
d\left(q, x_{n}\right) & =d\left(f q, x_{n}\right) \leq s\left[d\left(f q, g x_{n}\right)+d\left(g x_{n}, x_{n}\right)\right] \\
& =\frac{s}{s^{\varepsilon}} M_{s}\left(q, x_{n}\right)+s d\left(g x_{n}, x_{n}\right)
\end{aligned}
$$


where

$$
\begin{aligned}
M_{s}\left(q, x_{n}\right) & =\max \left\{\begin{array}{c}
d\left(S q, T x_{n}\right), d(f q, S q), d\left(g x_{n}, T x_{n}\right), \\
\frac{d\left(f q, T x_{n}\right)+d\left(S q, g x_{n}\right)}{2 s}
\end{array}\right\} \\
& =\max \left\{d\left(q, T x_{n}\right), 0, d\left(g x_{n}, T x_{n}\right), \frac{d\left(q, T x_{n}\right)+d\left(q, g x_{n}\right)}{2 s}\right\} \\
& \leq \max \left\{\begin{array}{c}
d\left(q, T x_{n}\right), s\left[d\left(g x_{n}, q\right)+d\left(q, T x_{n}\right)\right], \\
\frac{d\left(q, T x_{n}\right)+d\left(q, g x_{n}\right)}{2 s}
\end{array}\right\} \\
& =s\left[d\left(g x_{n}, q\right)+d\left(q, T x_{n}\right)\right] .
\end{aligned}
$$

Thus we have

$$
d\left(q, x_{n}\right) \leq \frac{s^{2}}{s^{\varepsilon}}\left[d\left(g x_{n}, q\right)+d\left(q, T x_{n}\right)\right]+s d\left(g x_{n}, x_{n}\right) .
$$

By triangular inequality,

$$
d\left(q, x_{n}\right) \leq \frac{s^{3}}{s^{\varepsilon}}\left[d\left(g x_{n}, x_{n}\right)+2 d\left(x_{n}, q\right)+d\left(x_{n}, T x_{n}\right)\right]+s d\left(g x_{n}, x_{n}\right) .
$$

So

$$
d\left(q, x_{n}\right) \leq \frac{1}{\left(1-\frac{2 s^{3}}{s^{\varepsilon}}\right)}\left[\left(\frac{s^{3}}{s^{\varepsilon}}+s\right) d\left(g x_{n}, x_{n}\right)+\frac{s^{3}}{s^{\varepsilon}} d\left(x_{n}, T x_{n}\right)\right] .
$$

On taking the limit as $n \rightarrow \infty$ we obtain

$$
\lim _{n \rightarrow \infty} d\left(q, x_{n}\right)=0 .
$$

\section{Conclusion}

In this paper, we given new fixed point theorems for mappings satisfying $b$-(E.A)-property in $b$-metric spaces. Our results extended $b$-(E.A)-property results in the literature. Also in last section we proved well-posedness result in $b$-metric spaces.

Authors' contributions

VO and SR have participated and prepared the manuscript. Both authors read and approved the final manuscript.

Author details

${ }^{1}$ Department of Business Administration, Faculty of Economics and Administrative Science, Artvin Coruh University, 08000 Artvin, Turkey. ${ }^{2}$ Faculty of Mechanical Engineering, University of Belgrade, Kraljice Marije 16, Belgrad 11120, Serbia. ${ }^{3}$ Department of Mathematics, State University of Novi Pazar, Novi Pazar, Serbia.

\section{Acknowledgements}

The authors would like to thank the referee for useful comments.

\section{Competing interests}

The authors declare that they have no competing interests. 
References

Aamri M, El Moutawakil D (2002) Some new common fixed point theorems under strict contractive conditions. J Math Anal Appl 270:181-188

Aghajani A, Abbas M, Roshan JR (2014) Common fixed point of generalized weak contractive mappings in partially ordered $b$-metric spaces. Math Slovaca 4:941-960

Ali J, Imdad M, Bahuguna D (2010) Common fixed point theorems in Menger spaces with common property (E.A). Comput Math Appl 60:3152-3159

Amini-Harandi A (2014) Fixed point theory for quasi-contraction maps in b-metric spaces. Fixed Point Theory 15(2):351-358

Bakhtin IA (1989) The contraction principle in quasimetric spaces. Funct Anal 30:26-37

Banach S (1922) Sur les opérations dans les ensembles abstraits et leur application aux équations intégrales. Fundam Math 3:133-181

Babu GVR, Sailaja PD (2011) Common fixed points of $(\psi, \varphi)$-weak quasi-contractions with property (E.A). Int J Math Sci Comput 1:29-37

Boriceanu M, Bota M, Petruşel A (2010) Multivalued fractals in b-metric spaces. Cent Eur J Math 8(2):367-377

Czerwik S (1993) Contraction mappings in b-metric spaces. Acta Math Inform Univ Ostrav 1:5-11

Ding HS, Imdad M, Vujaković J, Radenović S (2015) On some fixed point results in b-metric, rectangular and $b$-rectangular metric spaces. Arab J Math Sci. doi:10.1016/j.ajmsc.2015.05.003

Ding HS, Ozturk V, Radenović S (2015) On some new fixed point results in b-rectangular metric spaces. J Nonlinear Sc Appl 8:378-386

Hussain N, Shah MH (2011) KKM mappings in cone b-metric spaces. Comput Math Appl 62:1677-1684

Hussain N, Đorić D, Kadelburg Z, Radenović S (2012) Suzuki-type fixed point results in metric type spaces. Fixed Point Theory Appl. doi:10.1186/1687-1812-2012-126

Hussain N, Parvaneh V, Roshan JR, Kadelburg Z (2013) Fixed points of cyclic $(\psi, \varphi, L, A, B)$-contractive mappings in ordered b-metric spaces with applications. Fixed Point Theory Appl. doi:10.1186/1687-1812-2013-256

Jovanović M, Kadelburg Z, Radenović S (2010) Common fixed point results in metric-type spaces. Fixed Point Theory Appl 2010:978121

Jungck G (1986) Compatible mappings and common fixed points. Int J Math Sci 9:771-779

Khamsi MA, Hussain N (2010) KKM mappings in metric type spaces. Nonlinear Anal 73:3123-3129

Khan MS, Swaleh M, Sessa S (1984) Fixed point theorems by altering distances between the points. Bull Aust Math Soc 30(1):1-9

Kir M, Kiziltunc H (2013) On some well known fixed point theorems in b-metric spaces. Turk J Anal Number Theory $1(1): 13-16$

Nazir T, Abbas M (2014) Common fixed points of two pairs of mappings satisfying (E.A)-property in partial metric spaces. $J$ Inequal Appl 2014:237

Ozturk V, Turkoglu D (2015) Common fixed point theorems for mappings satisfying (E.A)-property in b-metric spaces. J Nonlinear Sci Appl 8(1):127-1133

Ozturk V, Turkoglu D (2015) Fixed points for generalized $\alpha-\psi$-contractions in $b$-metric spaces. J Nonlinear Convex Anal 16(10):2059-2066

Radenović S, Kadelburg Z (2011) Quasi-contractions on symmetric and cone symmetric spaces. Banach J Math Anal 5(1):38-50

Radenović S, Kadelburg Z, Jandrlić D, Jandrlić A (2012) Some results on weakly contractive maps. Bull Iran Math Soc 38(3):625-645

Roshan JR, Parvaneh V, Shobkolaei N, Sedghi S, Shatanawi W (2013) Common fixed points of almost generalized $(\psi, \varphi)_{s}$ -contractive mappings in ordered $b$-metric spaces. Fixed Point Theory Appl. doi:10.1186/1687-1812-2013-159

Roshan JR, Parvaneh V, Kadelburg Z (2014) Common fixed point theorems for weakly isotone increasing mappings in ordered b-metric spaces. J Nonlinear Sci Appl 7:229-245

Stanić MP, Cvetković AS, Simić S, Dimitrijević S (2012) Common fixed point under contractive condition of Ćirić's type on cone metric type space. Fixed Point Theory Appl. doi:10.1186/1687-1812-2012-35

\section{Submit your manuscript to a SpringerOpen ${ }^{\odot}$ journal and benefit from:}

- Convenient online submission

- Rigorous peer review

- Immediate publication on acceptance

- Open access: articles freely available online

- High visibility within the field

- Retaining the copyright to your article

Submit your next manuscript at $\boldsymbol{\nabla}$ springeropen.com 